\title{
Comparison of Different Fuel Compositions for a Research Reactor with Thermal Power of up to $10 \mathrm{MW}$
}

\section{Levchenko Yu. V., Zevyakin A.S., Karazhielievskaia Yu.E., and Terekhova A.M.}

Department of Nuclear Physics and Technology, Obninsk Institute for Nuclear Power Engineering of the National Research Nuclear University MEPhl, Studgorodok 1, Obninsk, Kaluga region, 249040, Russia

\section{Abstract}

In this article the prospect of using carbide fuel in a research reactor for export to countries with developing nuclear power is consider. The choice of a fuel composition for a research reactor is an important part in substantiating of the neutron-physical and economic characteristics of a reactor facility, and is also an important part of

Corresponding Author: Levchenko Yu. V.

YVLevchenko@mephi.ru

Received: 23 December 2017

Accepted: 15 January 2018

Published: 21 February 2018

Publishing services provided by Knowledge $\mathrm{E}$

(c) Yulia Levchenko et al. This article is distributed under the terms of the Creative Commons Attribution License, which permits unrestricted use and redistribution provided that the original author and source are credited.

Selection and Peer-review under the responsibility of the AtomFuture Conference Committee

\section{G OPEN ACCESS} the control-dependent self-sustaining fission chain reaction in a nuclear reactor that affects the specifics of management. For reducing the economic component in the design of this reactor core of the research reactor, structural materials and design solutions are used that have extensive experience in domestic power engineering. In this work $\mathrm{UO}_{2}-\mathrm{ThO}_{2}$ and $\mathrm{PuO}_{2}-\mathrm{ThO}_{2}$ was selected as the considered fuel compositions. In the course of the study, characteristics were obtained for a burnup of the fuel compositions under study, the initial reserve of reactivity and the duration of the fuel campaign.

Keywords: no-transshipment campaign, research reactors, reactivity margin, delayed neutron fraction, fuel composition

\section{Introduction}

Presently there is a noticeable interest in research reactors for usage in various areas of science and technology. One of the most actual is the market of radioisopic products in medicine. From the point of view of nuclear medicine, the following isotopes are of interest: ${ }^{90} \mathrm{Y},{ }^{188} \mathrm{Re},{ }^{99 m} \mathrm{Tc},{ }^{99} \mathrm{Mo},{ }^{68} \mathrm{Ga}$ and others. A nuclear reactor with a thermal power of up to $10 \mathrm{MW}$ with a fuel campaign no less than 10 years will allow to reduce the cost of handling fresh and spent nuclear fuel, as well as partially solve the problem of accounting, control and non-proliferation of nuclear materials. The purpose of the 
present research is to develop the concept of a serial reactor designed to produce radioisotope products, potentially capable to overcome the threshold of commercialization. Due to the fact that the reactor is expected to be operated in countries with low experience in the use of nuclear technologies, one of the most important criteria is the requirement for operation without refueling during a long campaign.

\section{Materials and Methods}

As the prototype serial reactors VVR and IRT [1] was chosen. The thermal capacity of the reactor is up to $10 \mathrm{MW}$. The size of the reactor tank is selected from the condition of a low level of activation of its material at the end of the campaign, permitting general industrial reprocessing without burial. The reactor core consists of the shortened fuel assemblies of the VVER-440 reactor [2], which allows organizing their production on existing equipment. The active zone contains 85 shortened fuel assemblies with a beryllium reflector located around the fuel assembly. Reactor core height $156 \mathrm{~cm}$, reactor core diameter $146 \mathrm{~cm}$. Cartogram of the core of a research reactor is shown in Figure 1.

Serpent (PC Serpent) (Finland) [3], which implements the Monte Carlo method, was used for calculation. The Serpent PC uses area geometry to describe complex systems very similar to the MCNP program (USA). This means that the geometry is divided into separate levels that are built independently and can be nested inside each other. This approach allows you to divide complex geometry into simpler parts, which are much easier to build.

The Serpent software package reads neutron interaction data with cores from neutron data libraries in the ACE format. A typical library package contains libraries in the ACE format based on the evaluated neutron data libraries JEF-2.2, JEFF-3.1, ENDF / B-VI.8 and ENDF / B-VII for several temperatures. In addition, the Serpent PC has a built-in algorithm for accounting for the Doppler effect, which allows one to take into account the dependence of neutron interaction cross sections with the medium on its temperature [4].

The use of promising fuel compositions can lead to an increase in the campaign of the reactor. The paper considers two types of fuel for a research reactor: $\mathrm{UO}_{2}-\mathrm{ThO}_{2}$ and $\mathrm{PuO}_{2}-\mathrm{ThO}_{2}$. The effect of the choice of the fuel composition on the neutron-physical and thermal-hydraulic characteristics of the core of the research reactor with a capacity of $10 \mathrm{MW}$ is considered. 
This type of fuel was previously used in thermal neutron reactors. Table 1 presents light-water reactors that operate with thorium fuel at US nuclear power plants in the last century [5]. In Russia, a study was conducted on the possibility of using thorium fuel in VVER-100o reactors [6]. It is worth noting the difference in the physical properties of the compounds of uranium, thorium and plutonium (Table 2) [7].

TABLE 1: Light water reactors working with thorium fuel at US nuclear power plants.

\begin{tabular}{|c|c|c|c|c|}
\hline NPP & Type of reactor & Power (thermal), MW & Fuel & Operating period \\
\hline Indian Point & BWR & 60 & $\mathrm{ThO}_{2}-\mathrm{UO}_{2}(93 \%$ обог. U) & $1962-1974$ \\
\hline Elk River & PWR & 615 & $\mathrm{ThO}_{2}-\mathrm{UO}_{2}(93 \%$ обог. U) & $1964-1968$ \\
\hline LWBR & PWR & 237 & $\mathrm{ThO}_{2}-{ }^{233} \mathrm{UO}_{2}$ & $1977-1982$ \\
\hline
\end{tabular}

TABLE 2: Physical properties of uranium, thorium and plutonium compounds.

\begin{tabular}{l|r|r|r} 
Properties & $\mathrm{ThO}_{2}$ & $\mathrm{UO}_{2}$ & $\mathrm{PuO}_{2}$ \\
\hline Mass density, $\mathrm{g} / \mathrm{m}^{3}$ & 10 & 10.96 & 11.5 \\
\hline Fusioning temperature, ${ }^{\circ} \mathrm{C}$ & 3300 & 2760 & 2400 \\
\hline Thermal conduction at $600{ }^{\circ} \mathrm{C}, \mathrm{kcal} / \mathrm{m}^{2} * \mathrm{~h} *{ }^{\circ} \mathrm{C}$ & 2.7 & 3.0 & 3.0
\end{tabular}

TABLE 3: Materials of the reactor core.

Options
Coolant
Moderator
Reflector
Fuel pin cladding
Fuel composition 1
Volume of UO 2 -fuel in mixture
Fuel enrichment by ${ }^{235} \mathrm{U}$
Fuel composition 2
Volume of PuO2 -fuel in mixture
Composition of plutonium
Pu238/Pu239/Pu240/Pu241/Pu242

Value
Water
Water
Beryllium
$\mathrm{Zr}+\mathrm{Nb}$
$\mathrm{UO}_{2}+\mathrm{ThO}_{2}$
0.35
0.195
$\mathrm{PuO}_{2}+\mathrm{ThO}_{2}$
0.1
$0.005 / 0.6 / 0.245 / 0.109 / 0.041$


TABLE 4: The change in nuclear concentrations $\left(10^{24}\right.$ nuclei $\left./ \mathrm{cm}^{3}\right)$ of some heavy isotopes for nuclear fuel campaigns for $\mathrm{UO}_{2}-\mathrm{ThO}_{2}$ and $\mathrm{PuO}_{2}-\mathrm{ThO}_{2}$ fuel compositions.

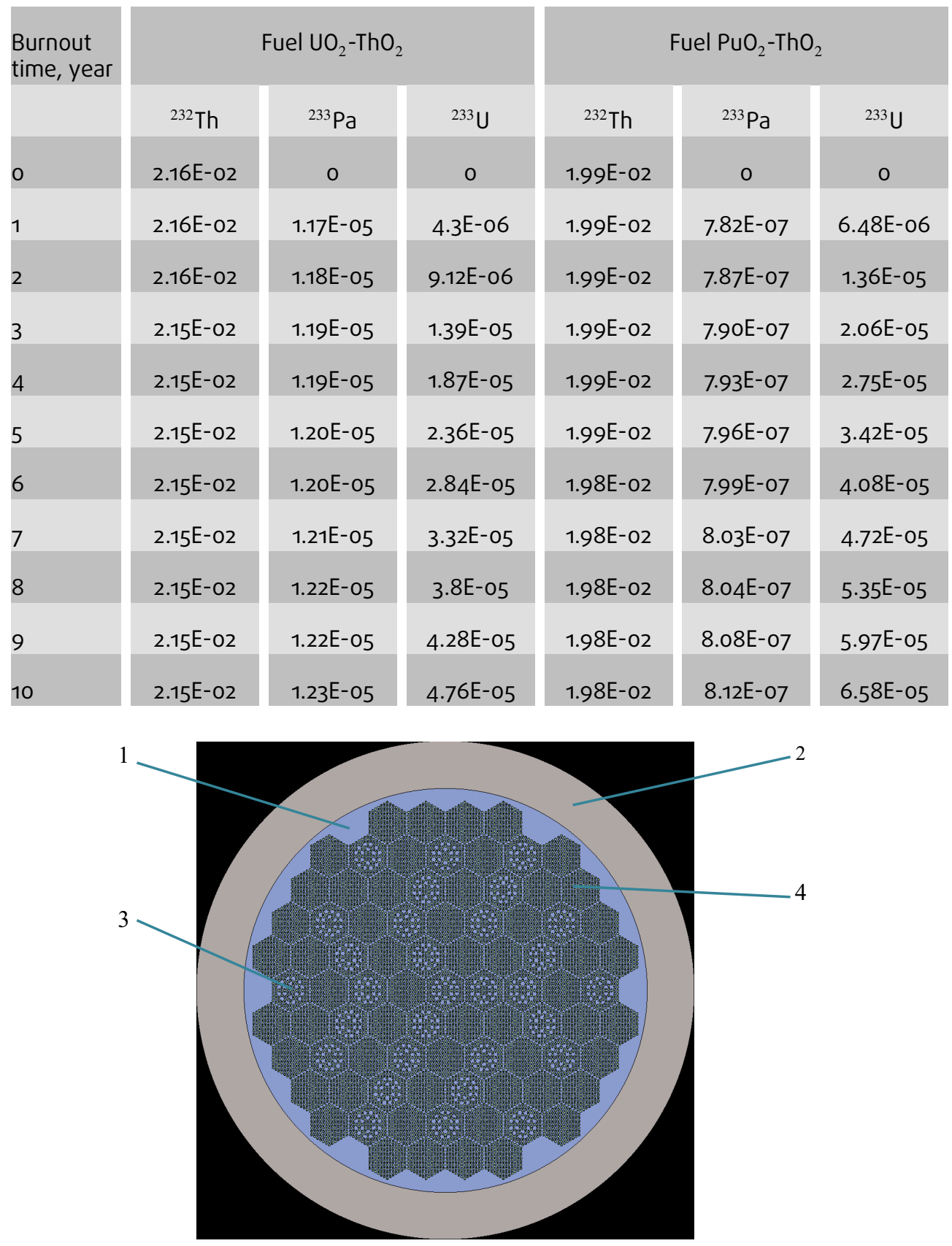

Figure 1: Cartogram of the core of the research reactor. 1 - Moderator; 2 - beryllium reflector; 3 - fuel assembly guide channels; 4 - fuel assembly.

\section{Results - Discussion}

The preliminary calculations have shown that the fuel should contain 14\% UO2 and $86 \% \mathrm{ThO}_{2}$ to the research reactor has operated without overload for 10 years at a power of $10 \mathrm{MW}$. Uranium enrichment by the isotope ${ }^{235} \mathrm{U}$ will be $19.5 \%$. Such enrichment corresponds to IAEA requirements for reactor fuel [9]. 


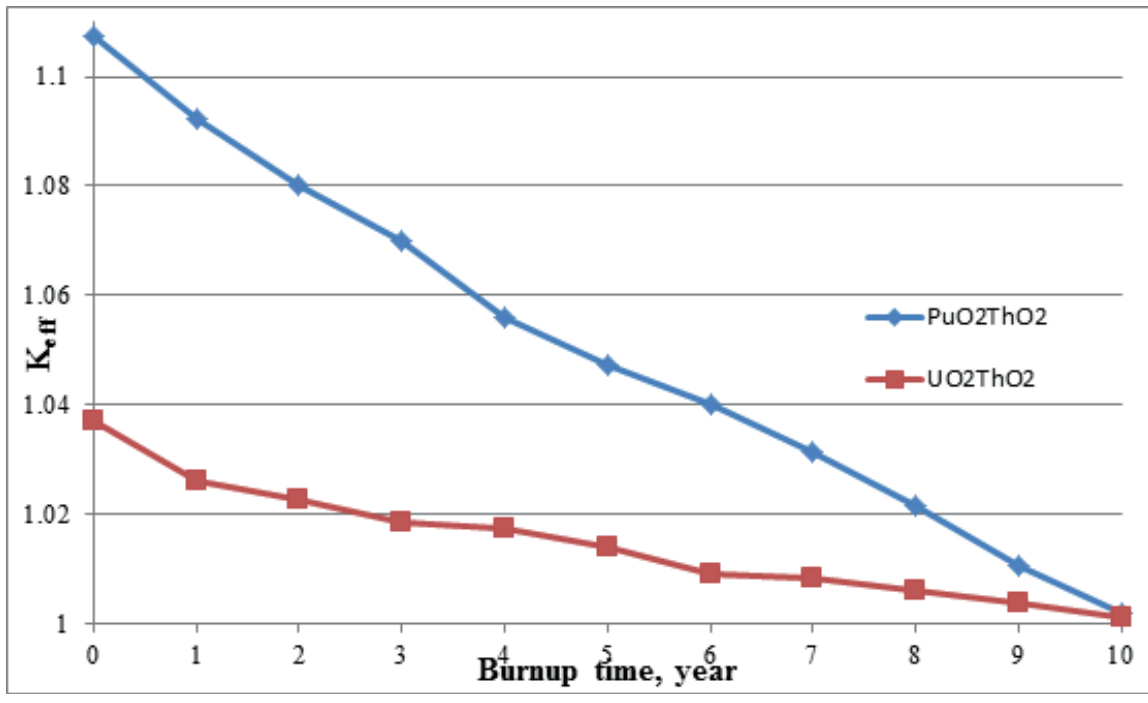

Figure 2: Dependence of the effective multiplication factor of the reactor core of a research reactor on the nuclear fuel campaign for $\mathrm{UO}_{2}-\mathrm{ThO}_{2}$ and $\mathrm{PuO}_{2}-\mathrm{ThO}_{2}$ fuel compositions.

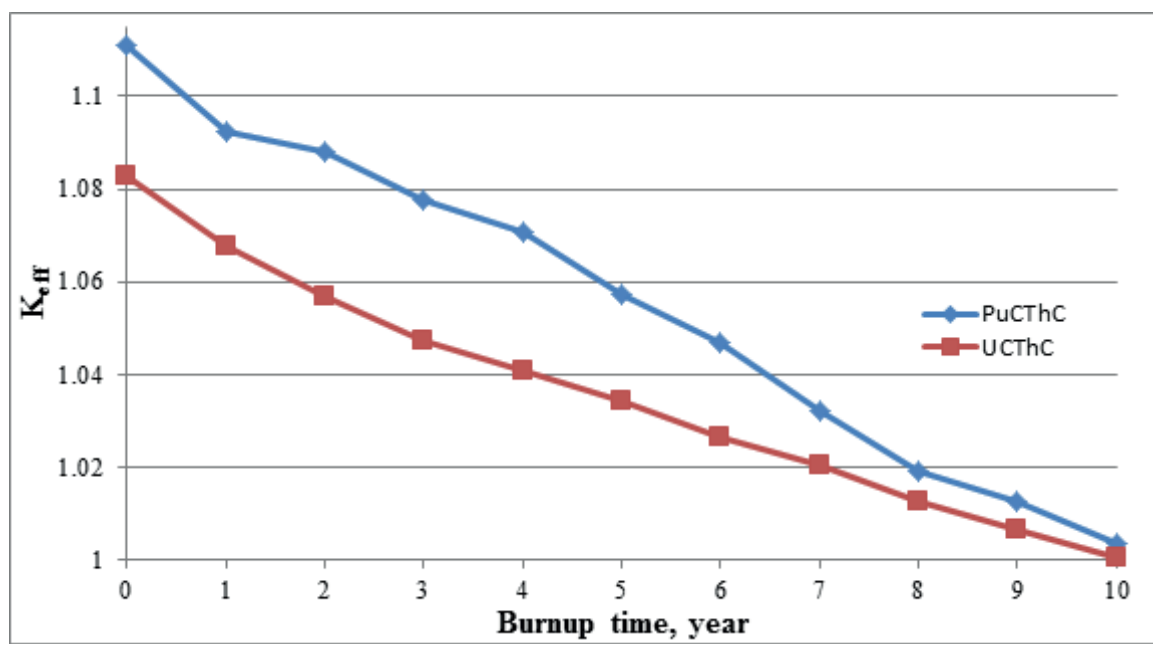

Figure 3: Dependence of the effective multiplication factor of the reactor core of a research reactor on the nuclear fuel campaign for UC-ThC и PuC-ThC fuel compositions.

To achieve the reserve of reactivity necessary to maintain a 10-year fuel campaign, the $\mathrm{PuO}_{2}$ content in the fuel mixture is $10 \%$. Detailed information of the composition of the fuel is presented in Table 3.

Figure 2 shows the dependence of the effective multiplication factor of the core of a research reactor on the nuclear fuel campaign for $\mathrm{UO}_{2}-\mathrm{ThO}_{2}$ and $\mathrm{PuO}_{2}-\mathrm{ThO}_{2}$ fuel compositions. It can be seen from the figure that the uranium-plutonium fuel campaign requires compensation for a smaller reactivity reserve at the beginning of the campaign at $3.5 \%$ versus $9.5 \%$ for plutonium-thorium fuel, and therefore less absorbing material. 
The fuel composition $\mathrm{PuO}_{2}-\mathrm{ThO}_{2}$ has the problem of deficiency of delayed neutrons. The fraction of delayed neutrons in plutonium-thorium fuel is $0.210 \%$, which is significantly lower compared with $0.672 \%$ in uranium load [8].

For comparison, Table 3 shows the changes in nuclear concentrations of some heavy isotopes ( ${ }^{232} \mathrm{Th},{ }^{233} \mathrm{~Pa},{ }^{233} \mathrm{U}$ ) during the nuclear fuel campaign for $\mathrm{UO}_{2}-\mathrm{ThO}_{2}$ and $\mathrm{PuO}_{2}-$ $\mathrm{ThO}_{2}$ fuel compositions.

The possibility of using carbide fuel with the following parameters was considered in the paper: $(\mathrm{Pu}+\mathrm{Th}) \mathrm{C}$ (PuC in the mixture is 4.5\%), $(\mathrm{U}+\mathrm{Th}) \mathrm{C}$ (PuC in the mixture is $15 \%$ ). - Dependence of the effective multiplication factor of the core of the research reactor on the nuclear fuel campaign for UC-ThC and PuC-ThC fuel compositions is shown in Figure 3.

The most common carbide compounds are UC and PuC monocarbides. Their density is somewhat higher than that of dioxide and is $\sim 14 \mathrm{~g} / \mathrm{cm} 3$. Thermal conductivity is close to the thermal conductivity of metallic uranium and is $\sim 15-20 \mathrm{kcal} /$ ( $\mathrm{m}$ hour ${ }^{\circ}$ S), i.e. $\sim 10$ times higher than that of U02. The melting point is also high $\left(\sim 2450^{\circ}\right.$ C), which makes it possible to operate this fuel at temperatures up to $\sim 2200^{\circ} \mathrm{C}$ [10]. But in this work, the operating temperature of the fuel is $260^{\circ} \mathrm{C}$. The main part of the research on the application of carbide fuel in nuclear reactors was carried out for reactors with a fast spectrum. In this paper, carbide fuel is used for a thermal reactor.

\section{Conclusion}

The simple arrangement of the reactor, the absence of a pressure-bearing housing, the use of a cheap coolant (water), a small number of activated structural materials, the relative compactness of the plant as a whole, and the use of common industrial enrichment fuel make the research reactor concept attractive not only from a technical, but also an economic point of view. The use of fuel with enrichment below $20 \%$ allows to ensure export potential.

Calculations showed that, from the point of view of neutron-physical characteristics, the use of oxide fuel is more effective. This will reduce the amount of absorbent material to compensate for initial reactivity.

*The research was carried out within the framework of the subsidy for financial support for the execution of the state task for the performance of public services. Theme No. 00-g-995-2203. 


\section{References}

[1] G. Bat, A. Kochenov, L.Kabanov. Research Nuclear Reactors. [Text] / G. Bat, A. Kochenov, L.Kabanov,- M.: Energoatomizdat, 1985. - 280 p.

[2] V. Budov, V. Farafonov. Designing the main equipment of nuclear power plants. [Text] / V. Budov, V. Farafonov ,- M.: Energoatomizdat, 1985. - 320 p.

[3] Jaakko Leppanen, PSG2/SERPENT - A Continious Energy Monte-Carlo Reactor Physics Burnup Calculation Code, - Helsinki: VTT Technical Research Centre of Finland, 2012.

[4] A. Stroganov, A. Kuryndin, at al. Using the SERPENT code to calculate Keff of uranium-water-graphite systems. // Questions of Atomic Science and Technology. Ser. Physics of nuclear reactors. - 2011. - Release. 3. - P. 72-76.

[5] S. Alekseev, V. Zaytsev. Thorium in nuclear power engineering. Moscow: TECHNOSPHERE, 2014. - 288p.

[6] N. Ponomarev-Stepnoy, G. Lunin, A. Morozov at al. The light-water thorium reactor VVER-T / // Atomic energy. - 1998. - Vol. 85, no. 4. - P. 263.

[7] V. Boyko, P. Gavrilov, I. Shamanin, M. Gerasim, V. Nesterov. Critical neutron-physical parameters of uranium-thorium and plutonium-thorium alloys, Izvestiya Tomsk Polytechnic University. 2006. T. 309. № 1.

[8] V. Murogov, M. Troyanov, A. Chmelev. Use of thorium in nuclear reactors. - M.: Energoatomizdat, 1983. $-96 \mathrm{C}$.

[9] IAEA Safety Standards NoNS-R-4, 2010

[10] Yu. Volkov. Physical and technical fundamentals of designing nuclear reactors: textbook, Obninsk, IATE, 1996. 